\title{
Novel Plantibodies Show Promise to Protect Citrus from Greening Disease
}

\author{
Joseph Krystel \\ U.S. Department of Agriculture, Agriculture Research Service, U.S. Horticultural Research \\ Laboratory, 2001 S. Rock Road, Fort Pierce, FL 34945 \\ Huawei Liu \\ Nanjing Agricultural University, College of Horticulture, The State Key Laboratory of Crop \\ Genetics and Germplasm Enhancement, Jiangsu, 210095, China \\ John Hartung \\ U.S. Department of Agriculture, Agriculture Research Service, Molecular Plant Pathology \\ Laboratory, 10300 Baltimore Avenue, Beltsville, MD 20705 \\ Ed Stover \\ U.S. Department of Agriculture, Agriculture Research Service, U.S. Horticultural Research \\ Laboratory, 2001 S. Rock Road, Fort Pierce, FL 34945
}

\begin{abstract}
Additional Index words. disease resistance, huanglongbing, $\mathrm{scFv}$
Abstract. Candidatus Liberibacter asiaticus (CLas), the bacteria responsible for citrus greening disease [huanglongbing (HLB)], has become a worldwide threat to citrus (Citrus sp.) production. HLB has proven difficult to study and treat because of the complex interactions between $C$ Las, the citrus host, and insect vectors. We have selected for single chain fragment variable (scFv) antibodies from a specialized bacteriophage library for binding activity against $C$ Las proteins InvA and TolC. Portions of each protein were chosen as antigens based on predicted binding availability and theorized necessary functions in pathogenicity. Binding affinity for individual scFv-expressing clones was confirmed by phage enzyme-linked immunosorbent assay (ELISA). The scFv sequences were stably transformed under the control of a tandem Cauliflower mosaic virus 35S (CaMV 2x35S) promoter by Agrobacterium tumefacien-mediated transformation into 'Carrizo' citrange (Citrus sinensis $\times$ Poncirus trifoliate), a citrus rootstock cultivar. Replicated plants of single transformations were inoculated by infestation with $C$ Las positive asian citrus psyllid (Diaphorina citri), a CLas vector. Inoculation and disease progression was monitored through quantitative real-time polymerase chain reaction. Inoculated transgenic plants showed significantly reduced $C$ Las titer compared with wild types. A subpopulation of transgenic plants displayed no measurable surviving bacteria after 12 months. Interestingly, individual replicated plants from the same transgenic events strongly segregated into two populations by resistance phenotype: a minority that were indistinguishable from wild-type plants and a majority that were highly resistant. Our results are the first step in developing a novel protection strategy for HLB.
\end{abstract}

Citrus greening (HLB) has emerged as the most significant disease in citrus (Citrus sp.) agriculture (Bové, 2006). The disease is associated with the phloem-limited fastidious gramnegative $\alpha$-proteobacteria, Candidatus Liberibacter species;

Received for publication 26 Apr. 2021. Accepted for publication 12 July 2021. Published online 7 September 2021.

Funding was provided by the Citrus Research and Development Foundation (CRDF), Lake Alfred, FL, and U.S. Department of Agriculture (USDA) Agricultural Research Service (ARS) Base Funding. Research was conducted in pursuance of project objectives approved by CRDF and the National Institute of Food and Agriculture. The manuscript was prepared in accordance with the USDA Office of Scientific Quality Review "Peer Review Best Practices." We thank K. Moulton, USDA-ARS for maintaining and providing asian citrus psyllid populations; Susan M. Koehler, USDA, Animal and Plant Health Inspection Service for a helpful review of the manuscript; and Jonathan Shao, USDA-ARS for bioinformatic analysis to identify the InvA and TolC epitopes used in this work. We also thank E. Cochrane and Y. Avila for greenhouse and lab support.

The authors declare that they have no conflicts of interest. USDA is an equal opportunity provider and employer. Mention of trade names or commercial products in this article is solely for the purpose of providing specific information and does not imply recommendation or endorsement by USDA. E.S. is the corresponding author. E-mail: ed.stover@usda.gov.

This is an open access article distributed under the CC BY-NC-ND license (https://creativecommons.org/licenses/by-nc-nd/4.0/). containing the citrus-infecting Candidatus Liberibacter africanus, Candidatus Liberibacter americanum, and Candidatus Liberibacter asiaticus (CLas) (Bastianel et al., 2005; Bové, 2006). CLas is the far more prevalent and virulent species (da Graça and Korsten, 2004; Gottwald, 2010). It is primarily vectored by the asian citrus psyllid [ACP (Diaphorina citri)] (Capoor et al., 1967). The bacteria and insect vector are now found in most citrus-growing regions, including the United States, China, and Brazil (Wang and Trivedi, 2013). HLB often has a devastating impact on infected citrus; causing a rapid decline, with loss of fruit yield and quality and potentially leading to tree death (Gottwald et al., 2007; McClean and Schwarz, 1970). No curative treatment for the disease has been discovered, and effective therapies have been elusive. There is also little to no naturally occurring resistance to HLB in commercially important scion cultivars of citrus (da Graça et al., 2016). A degree of tolerance has been reported for some cultivars (Miles et al., 2017; Stover et al., 2016). Industry efforts at controlling the disease have primarily included nutritional therapy for the plants and pesticide control of the ACP vector (Stansly et al., 2014).

HLB research and the development of effective treatments have been hindered by the unusual biology of $C$ Las. The bacteria 
has not yet been successfully maintained in a pure culture. Published examples of CLas culturing attempts were either nonpersistent or were only persistent when cocultured with other bacterial species (Davis et al., 2008; Merfa et al., 2019). The other bacteria may be serving to supplement metabolic needs that CLas is unable to meet on its own (Merfa et al., 2019). CLas and most Liberibacter species are placed within the provisional Candidatus taxa to indicate their incomplete characterization based primarily on genetic analysis and not culturing methods (Jagoueix et al., 1994; Murray and Stackebrandt, 1995). The lack of pure cultures severely limits the types of experimentation that can be performed on CLas. This is further hampered by the difficulty in measuring $C$ Las pathogenic effects. HLB has a long incubation period before symptoms develop, and citrus is a woody tree that requires years to reach maturity and properly assess disease progression. Many of the most pronounced symptoms are also easily conflated with unrelated nutritional deficiencies, drought stress, and other disorders (Bové, 2006; Cimò et al., 2013).

With no suitable culturing method for the bacteria, most CLas treatments must be tested in planta. Disease progression within the plant can then be tracked through visual symptomology and/or quantification of CLas titer. Although often used, both of these assessment methods have limitations. Visual symptoms, in addition to the aforementioned complications, are often reduced in severity when plants are grown in a controlled greenhouse environment with few other stresses. Titer analysis relies on detecting the unique CLas nucleic acid sequences with quantitative real-time polymerase chain reaction (qPCR) amplification of the $16 \mathrm{~S}$ ribosomal DNA (rDNA) gene (Li et al., 2006; Morgan et al., 2012). However, the bacteria are not evenly distributed either spatially or temporally in infected trees, requiring repeated sampling over time for adequate consistency. This variability is caused both by the migration of $C$ Las between root and leaf tissue (Johnson et al., 2014) and seasonal effects with lower overall titer and less detection in hotter months (Sauer et al., 2015; Zhang et al., 2013). The qPCR-based testing also does not distinguish between living and dead bacteria. Despite these complicating factors, CLas titer remains the primary means for tracking early disease progression.

Single chain fragment variable ( $\mathrm{scFv}$ ), which have been primarily used for medical research, are antibody analogs created through the fusion of the light-chain $\left(\mathrm{V}_{\mathrm{L}}\right)$ and heavy-chain $\left(\mathrm{V}_{\mathrm{H}}\right)$ variable coding regions of antibody genes. The $\mathrm{scFv}$ structure ensures that both antigen binding domains are present in equal concentrations and it is expressed efficiently in Escherichia coli. The $\mathrm{V}_{\mathrm{L}}$ and $\mathrm{V}_{\mathrm{H}}$ are attached by a short linker sequence to ensure assembly into a functional scFv molecule. Use of scFv technologies enable the in vitro selection and propagation of antibodies with the specificity of monoclonal antibodies (Barbas et al., 2001; Pavoni et al., 2007). These scFv fragments have been shown to associate singly or in multimers, influenced by the length of the linker (Hudson and Kortt, 1999). In an earlier project related to this study, scFvs that recognized CLas proteins were generated from a library of mouse (Mus musculus) antibody domains enriched in CLas binding activity (Yuan et al., 2016).

Phage display libraries in phagemid vectors can be screened by affinity selection against intact bacterial cells (Yuan et al., 2015), molecules present on the cell's exterior surface like lipopolysaccharide (Griep et al., 1998) or similarly available proteins (Yuan et al., 2016), depending on the objectives of the experimenter. The CLas genome has been sequenced, thus providing an annotated genome for the selection of proteins of interest (Duan et al., 2009). We used these data to select two proteins for use as antigens in affinity selection of scFvs. These proteins were predicted to be accessible for antibody binding and to play important roles in the infection process based on their similarity to previously characterized proteins. The targets were a homolog of TolC, which mediates removal of toxins from the bacterial cell (Blair and Piddock, 2009) and the virulence gene InvA which facilitates the invasion of host cells by Rickettsia prowazackii (Gaywee et al., 2003). The characterization of each protein, as well as their cloning, purification, and Sanger sequencing were as described previously (Liu et al., 2017).

TolC (WP_015452761.1) is highly homologous to NodT, an outer membrane efflux protein required for host nodulation by members of the Rhizobiaceae. NodT is one component of the resistance nodulation division (RND) efflux system. RND efflux proteins are widespread in gram-negative bacteria and function to remove toxic metabolites produced by the host from the bacterial cell (Blair and Piddock, 2009). TolC has been shown to be required for Xylella fastidiosa to colonize xylem in grapevine (Vitis vinifera). $X$. fastidiosa carrying TolC knockout mutations could not be recovered from grapevine, even minutes after inoculation (Reddy et al., 2007). TolC is assembled as an externally open pore in the outer membrane of the bacterium when docked in a multidrug efflux system (Blair and Piddock, 2009). Our $\mathrm{scFv}$ target is an externally exposed loop of the TolC pore opening (Blair and Piddock, 2009) identified by the dense alignment surface (DAS) transmembrane prediction server (Cserzö et al., 1997). Binding of scFv molecules to the protein at the open pore was expected to interfere with efflux function and allow lethal plant metabolites to accumulate in CLas cells.

The CLas genome encodes InvA(WP_015452601.1), a dinucleoside polyphosphate hydrolase with high homology to many such enzymes in pathogenic bacteria, including the Rhizobiales. A similar InvA protein (CAA14698.1) has been shown to accumulate within cells infected by $R$. prowazackii and to degrade dinucleoside polyphosphates (Gaywee et al., 2002, 2003). Dinucleoside polyphosphates accumulate in bacterial and eukaryotic cells in response to stress, leading to physiological effects including apoptosis (Vartanian et al., 1997). The InvA "invasin" protein is so named because it is required by intracellular pathogens to invade host tissue. It is not known if CLas InvA is secreted into the host cell, but if it were, the hydrolysis of dinucleoside polyphosphates of host origin would prevent the host cell from undergoing apoptosis and allow CLas to accumulate to the extraordinarily high levels observed in individual cells (Hartung et al., 2010).

Expression of antibodies in plants has been proposed as a means to control pathogens (Hiatt et al., 1989; Schots et al., 1992). Attempts have shown effective protection against a plant virus (Tavladoraki et al., 1993) but not against the corn stunt spiroplasma (Spiroplasma kunkelii) (Chen and Chen, 1998). The successful application of antibodies for therapeutic use against pathogens depends on careful selection of both the targeted epitope and the antibody. In this study, we report that transgenic expression of scFvs that recognize carefully defined epitopes from either InvA or TolC reduce the ability of CLas to replicate and maintain populations in transgenic 'Carrizo' citrange (Citrus sinensis $\times$ Poncirus trifoliate), a widely used rootstock for commercial citrus. Protection of the roots of CLas-infected trees may confer benefit to the scion because colonization and death of 
roots precedes the development of HLB symptoms in the scions of infected trees (Johnson et al., 2014). Transgenic rootstocks could also be readily used with a variety of commercial scion cultivars.

\section{Materials and Methods}

Statistical analysis. Comparisons were conducted using statistical software (JMP Genomics version 8.2; SAS Institute, Cary, NC). Greenhouse trials contained 10 biological replicates for each treatment. CLas cycle threshold $\left(\mathrm{C}_{\mathrm{T}}\right)$ data were compared by the Wilcoxon nonparametric analysis. The detached leaf assay experiment was replicated three times with consistent results. Higher likelihood to return an undetermined value for qPCR analysis of CLas $16 \mathrm{~S}$ rDNA was determined by Fisher's exact test.

Affinity Selection. In earlier work, six proteins from CLas were characterized and purified for potential use as antigens (Liu et al., 2017). As part of that effort, each protein was analyzed through bioinformatic approaches to predict which epitopes were more likely to be exposed on the surface of the protein and/or exterior of the cell for antibody binding. Among those proteins, TolC and InvA were selected as targets for immunotherapy. His- 6 affinity purified proteins were biotinylated, immobilized on streptavidin coated magnetic particles (M-280 Dynabeads; Invitrogen, Carlsbad, CA) and used as bait to select members of an antiCLas scFv library using the protocol as described in Yuan et al. (2016). The antiCLas library was generated by inoculating mice [Bagg albino/c (BALB/c)] with extract from CLas-infected ACP and PCR amplifying the variable regions of immunoglobulin $\mathrm{G}$ (Yuan et al., 2016).

Selections were cloned into the phagemid pKM19 for filamentous phage display and maintained in strain DH5 $\alpha \mathrm{F}$ E. coli for use (Pavoni et al., 2007). Each TolC and InvA binding clone was rescued through M13K07 helper phage infection. Binding affinity was characterized through phage ELISA by adsorbing 3 $\mu \mathrm{g}$ of antigen on an immunoassay plate, binding amplified phage preparation for $15 \mathrm{~min}$, three washes of phosphate buffered saline/tween, incubation with horseradish peroxidase conjugated secondary antibody and developing with 3,3',5,5'-tetramethylbenzidine liquid substrate (TMB solution; Sigma-Aldrich, St. Louis, MO). The phage ELISA protocols were previously reported when used to develop scFvs targeting other CLas proteins (Liu et al., 2017; Yuan et al., 2016). Methods of amplification and storage of the library followed standard protocols (Barbas et al., 2001). All animals were used in accordance with a protocol approved by the American Association for Laboratory Animal Science.

Expression CONSTRuCT. The scFv encoding regions of the pKM19 plasmid were amplified from affinity-selected clones using primers KM167 and KM180 (Pavoni et al., 2007). The PCR products were characterized by restriction fragment length analysis after Bst NI digestion. Multiple scFv antibody sequences selected against InvA and TolC were inserted into the plasmid vector pUSHRL (Supplemental Fig. 1). The pUSHRL plasmid is a binary vector suitable for agrobacterium (Agrobacterium tumefaciens) mediated transformation and expression of a cloned sequence under control of a tandem Cauliflower mosaic virus $35 \mathrm{~S}$ (CaMV 2x35S) promoter. The $\mathrm{scFv}$ containing sequences were amplified by PCR and cloned in-frame into pUSHRL at the SmaI and SpeI cloning sites between the CaMV 2x35S promoter and nopaline synthase (NOS) terminator. Primer sequences are shown in Table 1.

Agrobacterium and Citrus transformation. Ligated plasmids containing $\mathrm{scFv}$ genes were transformed into chemically competent E. coli cells (One Shot TOP10; Thermo Fisher Scientific, Waltham, MA) and individual PCR-confirmed transformed colonies were grown overnight at $37^{\circ} \mathrm{C}$. Supercoiled plasmid was recovered from $E$. coli cultures through spin column purification (QIAprep spin miniprep kit; Qiagen, Hilden, Germany) using the manufacturer's recommended protocol. Purified plasmid was used to transform $200 \mu \mathrm{L}$ of EHA-105 agrobacterium cells made competent by suspension in $20 \mathrm{~mm}$ calcium chloride and stored at $-80^{\circ} \mathrm{C}$ until use. Transformation was achieved using the freeze-thaw method (Hofgen and Willmitzer, 1988). Individual colonies were confirmed by PCR amplification of the inserted $\mathrm{scFv}$ sequence using primers specific for the CaMV $2 \times 35$ S promoter and NOS terminator (Table 1).

Agrobacterium cultures were used to transfect epicotyl segments of 'Carrizo' citrange with the scFv expression constructs (Hao et al., 2016). Putative transgenic shoots regenerated from the epicotyl segments were self-rooted and maintained under greenhouse conditions. Transgene insertion was checked by PCR amplification and subsequent sequencing using CaMV 2x35S and

Table 1. Primers used for generating single chain fragment variable ( $\mathrm{scFv}$ ) constructs and performing polymerase chain reaction (PCR) and quantitative real-time PCR analysis.

\begin{tabular}{|c|c|c|c|}
\hline Primer & Target & Strand & Sequence \\
\hline $\mathrm{T} 7$ & pET-102/D-TOPO & $\mathrm{F}$ & 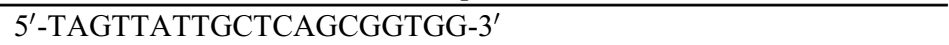 \\
\hline TrxFus & pET-102/D-TOPO & $\mathrm{R}$ & 5'-TTCCTCGACGCTAACCTG-3' \\
\hline 1314-F & TolC-scFv clone 1314 & $\mathrm{~F}$ & 5'-TGCCAGCTCGAGTGTAAG-3' \\
\hline $1314-\mathrm{R}$ & TolC-scFv clone 1314 & $\mathrm{R}$ & 5'-ACTCCAGAAGCCAGGTTG-3' \\
\hline 1419-F & InvA-scFv clone 1419 & $\mathrm{~F}$ & 5'-GGAGTGGATGGGCTACATAAG-3' \\
\hline 1419-R & InvA-scFv clone 1419 & $\mathrm{R}$ & 5'-GGATGTGTCTCGAGTGATAGAG-3' \\
\hline d35S-3 & pUSHRL 2x35s pro. & $\mathrm{F}$ & 5'-GACGCACAATCCCACTATCC-3' \\
\hline 3 nos-3 & pUSHRL NOS term. & $\mathrm{R}$ & 5'-TTTGCGCGCTATATTTTGTTT-3' \\
\hline CL1f & CLas 16 s rDNA & $\mathrm{F}$ & 5'-CTTACCAGCCCTTGACATGTATAGGA-3' \\
\hline CL1r & CLas 16 s rDNA & $\mathrm{R}$ & 5'-TCCCTATAAAGTACCCAACATCTAGGTAAA-3' \\
\hline CD-F & Citrus Dehydrogenase & $\mathrm{F}$ & 5'-TGAGTACGAGCCGAGTGTTG-3' \\
\hline CD-R & Citrus Dehydrogenase & $\mathrm{R}$ & 5'-CTGGTGGATCGGTGAAGTTT-3' \\
\hline $\mathrm{scFv-F}$ & pKM19 scFv region & $\mathrm{F}$ & 5'-ATCCCGGGGGCTCGTATGTTGTGTGGA-3' \\
\hline scFv-R & pKM19 scFv region & $\mathrm{R}$ & 5'-CTAGTCTTACAGCTCGTCCTTTAGCCCCCTTATTAGCGTTTG-3' \\
\hline
\end{tabular}


NOS terminator specific primers. The mRNA expression was checked with construct sequence specific primers (Table 1).

HLB CHALLENGE AND QPCR ANALYSIS. Clonal replicates of each transgenic line were inoculated through no-choice caged feeding of CLas-infected ACP. Each replicate, which was composed of a rooted cutting of the original event, was grown in a single cell flat (Cone-tainer SC10; Stuewe \& Sons, Tangent, OR). Groups of 10 replicates of each transgenic line and 20 wild-type (WT) control plants, all of the same size and maturity and grown adjacently were used. At $7 \mathrm{~d}$ before inoculation, plants were trimmed to a height of $\approx 15 \mathrm{~cm}$ to reduce damage from caging and stimulate new flush. Each plant was then confined in a ventilated polycarbonate tube of $4 \mathrm{~cm}$ diameter and 20 $\mathrm{cm}$ height, fitted over the top of the cell and containing 20 adult ACP for a period of 2 weeks. ACP were collected from the CLas-infected colonies maintained at the U.S. Department of Agriculture, Agricultural Research Service facility in Fort Pierce, FL. Colonies were raised on CLas-infected citrus and were assessed for CLas titer biweekly by qPCR analysis of 30 randomly selected adults. After infestation, ACP were removed through suction and the plants treated with a topical insecticide. Plants were then maintained in an ACP-free greenhouse for the 12-month term of the experiment.

Leaf samples were collected at 3, 6, 9, and 12 months after removal of ACP and transfer to the greenhouse. At each time point, the midribs of three fully expanded mature leaves of the penultimate flush from each plant were collected and pooled. Midribs were used for their high proportion of phloem; thus they are likely reservoirs of the phloem limited CLas cells. Root samples were also collected at 12 months. Fibrous roots of $\approx 1 \mathrm{~mm}$ diameter were taken from all four quadrants of the root mass. Midrib and root DNA were extracted using a DNA purification kit (Nucleospin Plant II kit; Macherey-Nagel, Düren, Germany), with root samples extracted using the manufacturer-suggested modifications in the "Genomic DNA from plant" protocol, which included increasing the volume of lysis buffer PL1 to 800 $\mu \mathrm{L}$, homogenizing samples with steel beads in an automated tissue homogenizer (Geno/Grinder 2010; SPEX SamplePrep, Metuchen, NJ) for $3 \times 4 \mathrm{~min}$ at $1600 \mathrm{rpm}$, and incubating at $70{ }^{\circ} \mathrm{C}$ for $30 \mathrm{~min}$.

CLas was quantified by qPCR analysis with USHRL-CL1f and USHRL-CL1r primers targeting the CLas 16S rDNA (McKenzie and Shatters, 2009) and reported as $C_{T}$ values. $C_{T}$ is a measurement of the number of amplification cycles needed before detection and is inversely proportional to bacterial titer. The qPCR analysis was conducted on a qPCR system (Applied Biosystems ABI-7500, Thermo Fisher Scientific) using the parameters: hold at $95^{\circ} \mathrm{C}$ for $10 \mathrm{~min}$ and 40 cycles $\left(95^{\circ} \mathrm{C}\right.$ for 15 $\mathrm{s}, 60^{\circ} \mathrm{C}$ for $60 \mathrm{~s}$ ). Each $25-\mu \mathrm{L}$ reaction contained $2 \mu \mathrm{L}$ of DNA template normalized to $50 \mathrm{ng} \cdot \mu \mathrm{L}^{-1}, 2 \mu \mathrm{L}$ of $10 \mu \mathrm{M}$ F/R primer mix, $8.5 \mu \mathrm{L}$ nuclease free water, and $12.5 \mu \mathrm{L}$ of $2 x$ SYBR green reagent mix (PowerUp SYBR Green Master Mix 2x, Thermo Fisher Scientific). A standard curve for the primers was determined under these conditions and found to be $\log _{10}$ (copy number $)=-0.2888\left(\mathrm{C}_{\mathrm{T}}\right)+11.659$. DNA from sample extractions was quantified using a spectrophotometer (NanoDrop 1000, Thermo Fisher Scientific) and diluted to the required $50 \mathrm{ng} \cdot \mu \mathrm{L}^{-1}$ in nuclease free water. Citrus dehydrogenase was amplified as an endogene control to confirm DNA quality for each sample. Each run contained a no-template negative control and a known positive control extracted from highly symptomatic HLBinfected rough lemon (Citrus jambhiri).

Detached Leaf ASSAy. Mature fully expanded, but not hardened, leaves were collected. Petioles were trimmed and placed into 1.5-mL eppendorf tubes with caps removed, filled with sterilized tap water, and the openings enclosed with a double layer of flexible film (parafilm; Bemis Co., Neenah, WI) wrapped around the petioles. Leaves and tubes were then placed into 50$\mathrm{mL}$ conical tubes with mesh caps. A group of 20 CLas-infected ACP were introduced into each setup for infestation and no choice feeding. ACP were sourced from the same colonies as used for HLB challenges. All detached leaf setups were incubated at $25^{\circ} \mathrm{C}, 12 \mathrm{~h}$ light/dark photoperiod. Each setup was observed daily, eppendorf tubes were refilled with water via pasture pipette as needed. After $7 \mathrm{~d}$, ACP were removed by suction, and each individual leaf midrib underwent DNA extraction and qPCR analysis as described earlier.

\section{Results}

We have identified scFv antibodies that bind to the CLas proteins InvA and TolC. Both proteins were selected as likely to play a critical role in the host/pathogen interactions of citrus and CLas; having a high degree of similarity (Madeira et al., 2019) to identified virulence genes from $R$. prowazekii and Rhizobium sp. (Fig. 1). Regions characterized for antigen value were PCR amplified and the amplicon cloned into the $\mathrm{pET}$ vector system for expression in $E$. coli (Fig. 2). Clones were confirmed by Sanger sequencing. The enriched scFv library was selected for binding activity against expressed InvA and TolC fragments to generate multiple independent lines. The lines were isolated as phagemid pKM19 derivatives to produce an $\mathrm{scFv}$ with monospecific properties similar to a monoclonal antibody. Each scFv was tested for binding reactivity to the target protein by ELISA using vector only "captures" as negative control, the results expressed as absorption at $450 \mathrm{~nm}$ with a correction measurement for nonspecific absorption at $620 \mathrm{~nm}$ (Fig. 3). A large number of individual clones showing high binding affinity were produced.

Multiple independent $\mathrm{scFv}$ sequences were selected, including nine binding InvA fragments and 11 binding TolC fragments. Each sequence could behave differently under cellular conditions and testing multiple constructs increases the probability of conferring resistance. Transgenic citrus were generated using two of the scFv sequences; 18 lines expressing scFv-InvA1419 and six lines expressing scFv-TolC1314. Transfer DNA (T-DNA) insertion was confirmed by PCR and $\mathrm{scFv}$ mRNA expression levels were quantified by reverse transcriptase qPCR using the sequence specific primers (primers 1314-F, 1314-R, 1419-F, and 1419-R) listed in Table 1. For this initial series of phenotypic studies, we selected two events each from these two scFv constructs; TolC1314-A, TolC1314-B, InvA1419-A, and InvA1419-B. Independent events are selected to account for potential epigenetic influences of specific gene insertion sites. The mRNA expression levels were relatively consistent between events (Fig. 4). The selected transgenic lines showed vigorous growth and readily produced the rooted cuttings needed for replicated studies.

Testing showed the ability for ACP to transmit CLas into the plants was no different in ScFv expressing lines compared with WT citrus (Fig. 5). All experimental plants (both WT and transgenic) were successfully inoculated and confirmed $C$ Las positive by qPCR analysis at time points $>3$ months after ACP 
A

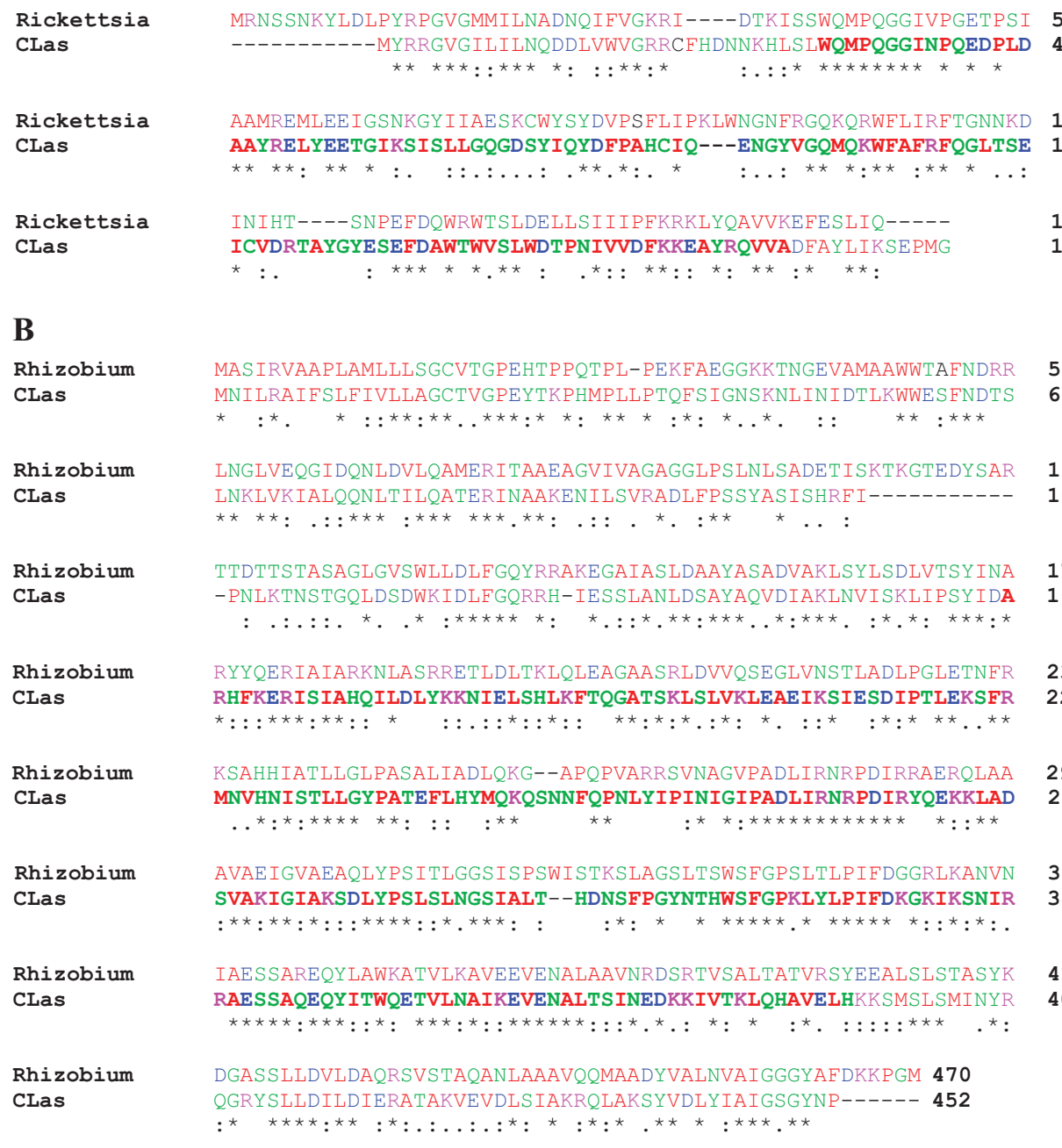

Fig. 1. Comparisons between Candidatus Liberibacter asiaticus (CLas) proteins and homologs. (A) Clustal Omega alignment (Madeira et al., 2019) showing similarity between of the gene products for Invasion protein A (CAA14698.1) from Rickettsia prowazekii and InvA (WP_015452601.1) from CLas. (B) Clustal Omega alignment of the gene products for NodT (TPA: nodulation protein, HCL64756.1) from Rhizobium species and CLas TolC [Tolerance to colicins (WP_015452761.1)]. Noted in bold are the regions from each peptide predicted to be exposed in the final in vivo conformation, which were cloned for antibody selection.

Transgenic plants expressing either TolC1314 or InvA1419 exhibited resistant phenotypes following nochoice ACP inoculation of rooted plants. Although all plants tested positive for CLas over the course of the experiment, the infection in transgenic lines was slower to progress (Table 2). Most WT plants tested positive for CLas rDNA amplification at 3 months (15 of 20 plants), whereas a majority of transgenic plants had not yet reached detectable levels. For TolC1314, $C$ Las was detectable in four of nine plants (one deceased) of line A and in four of 10 plants for line B. For InvA1419, CLas was detectable in three of 10 plants for line A and in four of 10 plants for line B. The average time after inoculation for CLas detection was 4.7 to 6.0 months in transgenic lines and 3.9 months for WT plants. Transgenic lines as a whole were significantly more likely to have undetectable levels of $C$ Las at 3 months $(P=0.008), 9$ months $(P=$ $0.02)$, and 12 months $(P=0.01)$ after inoculation using Fisher's exact test. Transgenic plants also carried lower $C$ Las titers (higher $\mathrm{C}_{\mathrm{T}}$ values) over the full course of the experiment at each time point (Table 2). The best performing lines of each construct, TolC1314-B and InvA1419-A, averaged a $98.5 \%\left(6.18 \mathrm{C}_{\mathrm{T}}\right)$ and $99.3 \%$ $\left(7.28 \mathrm{C}_{\mathrm{T}}\right)$ reduction in CLas titer respectively compared with the WT plants over the full 12-month period (estimated by copy number of CLas genomes amplified). CLas titer was varied for all treatments over the year of study, with the highest titers for both WT and transgenic populations

infestation. All amplifying samples had a $\mathrm{C}_{\mathrm{T}}$ of $\leq 37.0$. Exact quantification of Clas transmitted to whole plants was not possible through leaf sampling immediately following infestation because the bacterial cells are not evenly distributed. Therefore, transmission efficiency was directly tested using a detached leaf assay. Five individual detached leaves were harvested from noninfected transgenic plants and WT control plants. Leaves were inoculated through no-choice feeding by $20 \mathrm{ACP} / \mathrm{leaf}$ from a CLas-infected colony. Transmission was measured by two technical replicates of qPCR analysis of leaf midribs using CLas $16 \mathrm{~S}$ rDNA specific primers. In three repeated trials, no statistical difference was seen in CLas detectability/transmission between transgenic and WT leaves. Transmission efficiency was high, with both populations testing positive in $\approx 80 \%$ of leaves. When transmission was successful, nearly identical quantities of bacteria were transmitted to leaves; $C$ Las $\mathrm{C}_{\mathrm{T}}$ values of 32.4 for InvA1419-A, 32.5 for TolC1314-A and 33.0 for WT from a representative run (Fig. 5). observed in winter collections [December (6 months postinoculation)] and lower overall titer in warmer months (Table 2). Statistical separation between WT and transgenic plants was reduced by the high variation within the transgenic lines, which was most impactful in periods of lower overall titer, even when the average $\mathrm{C}_{\mathrm{T}}$ values remained well separated.

Results were not uniform within replicates of each transgenic line. Individual replicates segregated into two phenotypes based on disease progression and typified by the first detectable presence of CLas. Hereafter each group is referred to as "early onset" if CLas was detectable at 3 months and "late onset" if detection only occurred $>3$ months after inoculation. For each treatment line the distribution into late-onset and early-onset groups was as follows; WT: 5L/15E, TolC1314A: 5L/4E, TolC1314B: 6L/4E, InvA1419A: 7L/3E, and InvA1419B: 6L/4E. Late-onset transgenic plants continued to show lower $C$ Las titer through the course of the study. Statistical analysis strongly supported this variation within the transgenic populations. At all observed time 

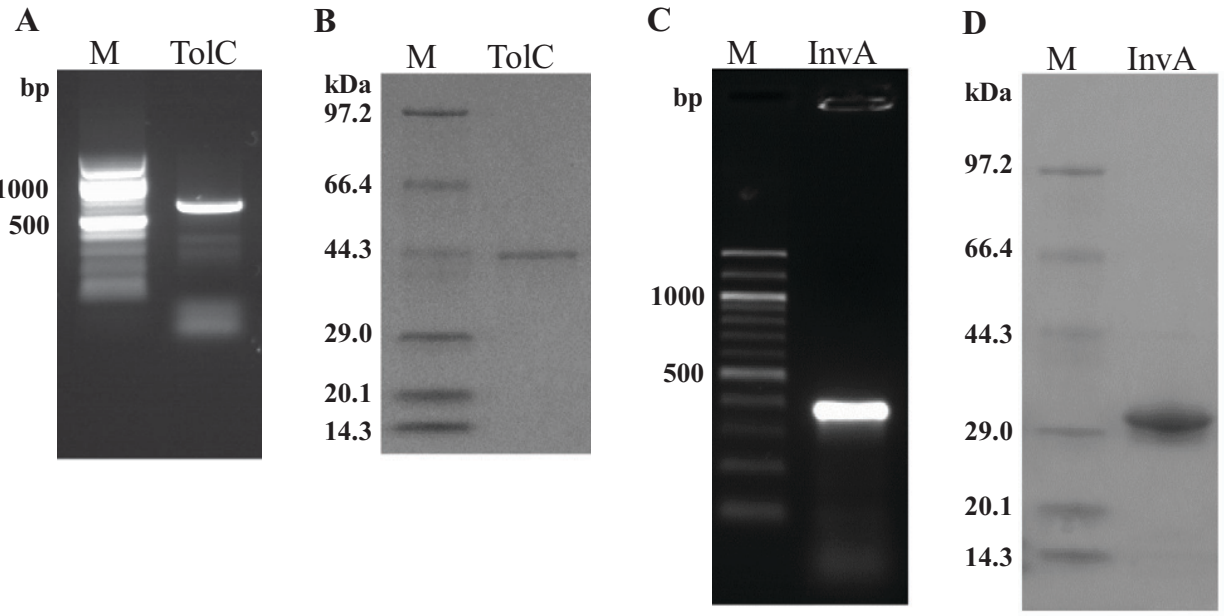

points after 3 months, the late-onset populations continued to show appreciably higher $C$ Las $\mathrm{C}_{\mathrm{T}}$ values compared with WT plants and early-onset plants from the same line (Table 3). This effect was unique to the transgenic populations and not seen in WT plants, with no statistical difference between $\mathrm{WT}_{\mathrm{E}}$ and $\mathrm{WT}_{\mathrm{L}}$ titers at 6 months $(P=0.89), 9$ months $(P=$ $0.42)$, or 12 months $(P=0.96)$.

When comparing root samples collected at the conclusion of the 12-month period, $\mathrm{C}_{\mathrm{T}}$ values were in general much higher than midrib samples (Table 3). With this low overall CLas titer, no significant difference was seen when comparing the average values between

Fig. 2. Cloning and purification of peptides used in single chain fragment variable ( $\mathrm{scFv}$ ) antibody selection. (A) A 681-bp fragment was polymerase chain reaction (PCR)-amplified from Candidatus Liberibacter asiaticus genomic TolC sequence and purified by agarose gel electrophoresis. The sequence was inserted into the pET102/D-TOPO vector system and cloned into Escherichia coli strain BL21 for protein expression. pET102/D-TOPO expresses the protein fragment as a fusion protein containing the 6-His affinity tag and V5 epitope tag. (B) Proteins were purified using a nickel-charged affinity resin purification system and visualized by denaturing polyacrylamide gel electrophoresis. The process was repeated for the $345 \mathrm{bp}$ fragment of InvA with (C) PCR and (D) purified fusion protein.

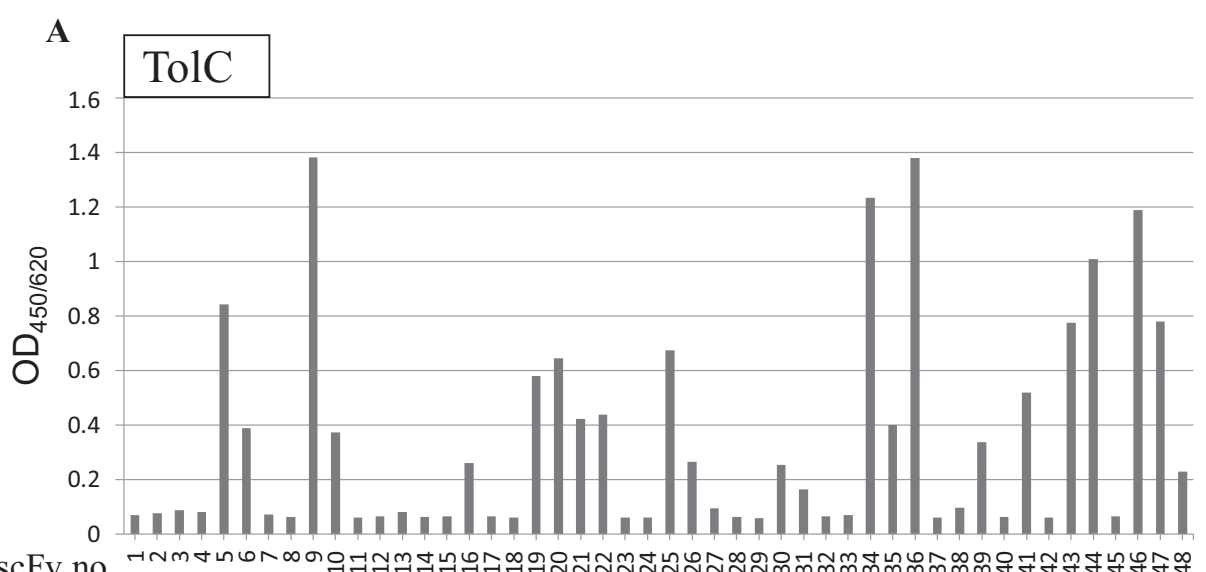

scFv no. ஈ

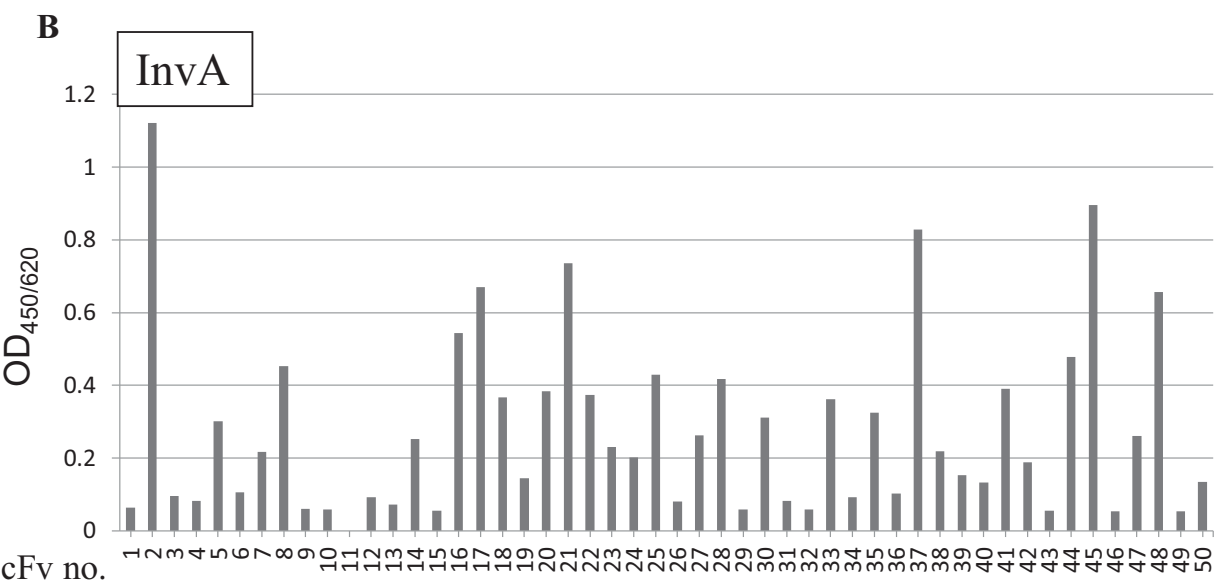
scFv no.

Fig. 3. Binding affinity of single chain fragment variable (scFv) antibodies targeting Candidatus Liberibacter asiaticus (CLas) proteins. Exposed regions from TolC and InvA were used as bait for three rounds of selection from an antiCLas enriched scFv library. Phage enzyme-linked immunoassays were performed with (A) 48 independent colonies from TolC scFv selection and (B) 50 colonies from InvA. Results expressed as the ratio of absorbance at 450 and $620 \mathrm{nM}\left(\mathrm{OD}_{450 / 620}\right)$. treatments. However, statistical analysis showed that transgenic plants were significantly more likely to return an undetermined (no amplification) result in root samples $(P=0.01)$ compared with WT. When grouping the root samples by first detection, the late onset transgenic populations also had reduced CLas titer in root tissues collected at 12 months. They showed significantly higher average $\mathrm{C}_{\mathrm{T}}$ values in roots compared with WT $(P=0.002-0.06)$ (Table 4$)$. No difference was seen in $C$ Las $\mathrm{C}_{\mathrm{T}}$ between $\mathrm{WT}_{\mathrm{E}}$ and $\mathrm{WT}_{\mathrm{L}}$ root samples $(P=1.00)$.

\section{Discussion}

Consumer demand has led the citrus industry to focus on a small number of cultivars with commercially desirable traits, which results in little genetic variation. Needed diversity must be added through breeding with more distant relatives (requiring multiple generations to achieve commercially viable fruit) or through transgenic methods. HLBrelated loss of root mass and subsequent susceptibility to stresses are significant modes of harm for the tree (Graham et al., 2013). Infected roots may also serve as a reservoir for bacteria that can spread to new flush (Johnson et al., 2014). Generation of a CLas resistant rootstock could directly protect from HLB-mediated root loss and support commercially important scion cultivars without the need for slow and costly deregulation of each scion cultivar. TolC and InvA are both highly promising targets for such efforts due to the strong probability that each has an indispensable role in host-pathogen interaction and their availability for binding by plantibodies. 
A

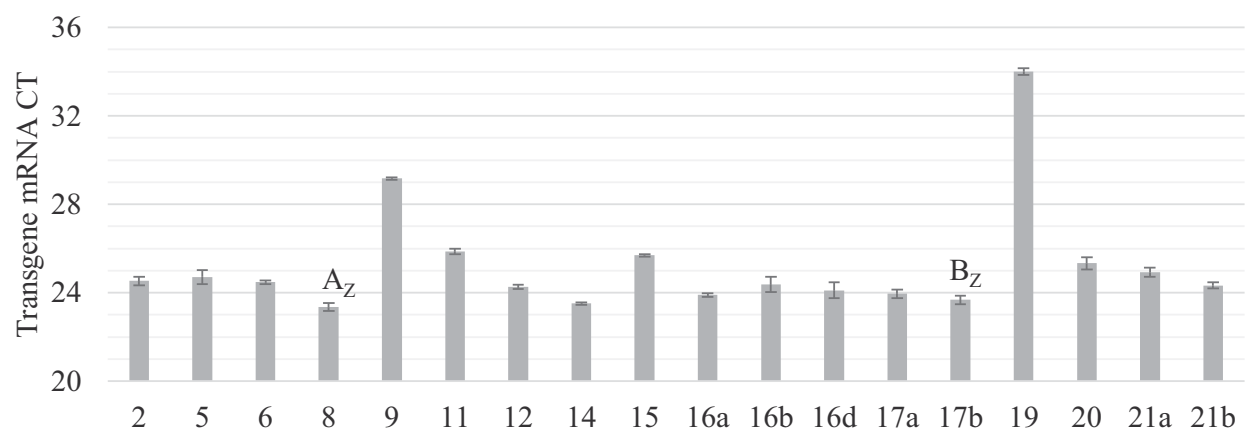

Event no.

scFv-InvA1419

Fig. 4. Relative expression in Explants of 'Carrizo' citrange transformed with the single chain fragment variable (scFv) constructs targeting the Candidatus Liberibacter asiaticus (CLas) proteins InvA (scFv-InvA1419) and TolC (scFv-TolC1314). Presence of scFv mRNA was confirmed by quantitative real-time polymerase chain reaction analysis using sequence specific primers. Transcript levels for individual (A) scFv-InvA1419 and (B) scFv-1314 events shown as the average cycle threshold $\left(\mathrm{C}_{\mathrm{T}}\right)$ and $\mathrm{SE}$ of three technical replicates. Mock transformed control plants had no transgene amplification. Two vigorously growing events from each construction (InvA1419 event 8, InvA1419 event 17b, TolC1314 event 4, and TolC1314 event 6) were replicated to generate transgenic the lines InvA1419-A, InvA1419-B, TolC1314-A, and TolC1314-B; marked as $\mathrm{A}_{\mathrm{Z}}$ and $\mathrm{B}_{\mathrm{Z}}$, respectively, in each graph. These four lines were used in trials with CLas inoculation by no-choice feeding of asian citrus psyllids.

A

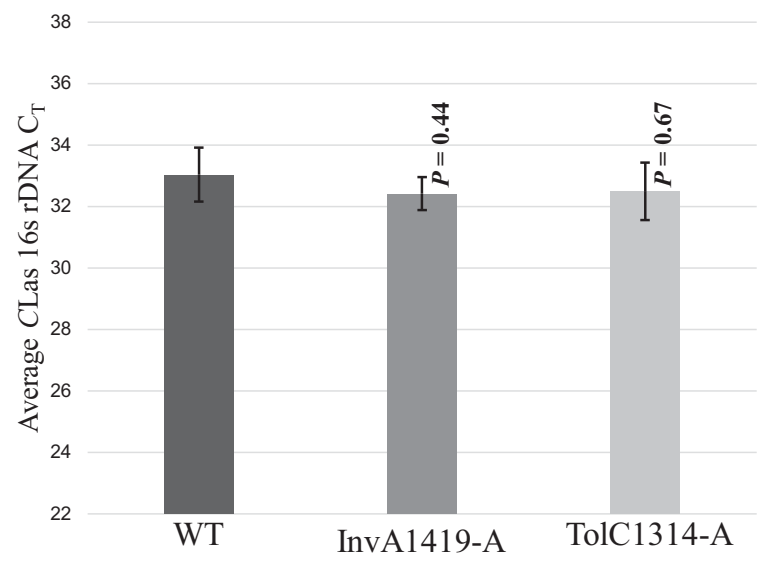

Fig. 5. Candidatus Liberibacter asiaticus (CLas) transmission efficiency as assessed in a detached leaf assay. Leaves from transgenic lines InvA1419-A and TolC1314-A and wild-type (WT) controls were used in a detached tissue assay for CLas transmission. Leaves from each line were inoculated through no choice feeding of CLas infected asian citrus psyllids for $3 \mathrm{~d}$, followed by a $4 \mathrm{~d}$ incubation period. (A) Midribs of each leaf were collected and CLas presence assayed by quantitative real-time polymerase chain reaction of the CLas $16 \mathrm{~S}$ ribosomal DNA (rDNA). Average cycle threshold $\left(\mathrm{C}_{\mathrm{T}}\right)$ values from a representative assay show no significant variation in transmission of CLas compared with WT controls by Wilcoxon method. The experiment was repeated three times with similar results. (B) The CLas transmission rate as measured by percentage of leaves with CLas rDNA amplification over the course of three repeated experiments was highly similar for both transgenic and WT leaves.
CLas transmission $[\%($ mean $\pm \mathrm{SE})]$

InvA1419-A $80 \pm 11.5$

TolC1314-A $73 \pm 6.7$
B

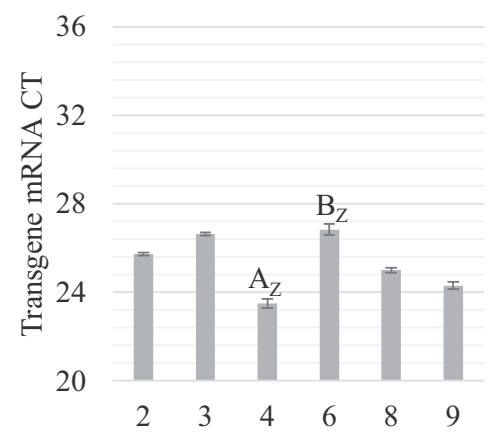

Event no.

These results do not appear to be caused by differences in inoculation efficiency because transgenic expression of $\mathrm{scFv}$ antibodies had no impact on ACP-mediated CLas transmission in detached leaf trials. Transgenic leaves were inoculated at the same rate and with the same inoculum of bacteria as nontransgenic leaves. These results are consistent with the whole plant HLB challenge where all transgenic plants were successfully inoculated and colonized by $C$ Las but maintained a lower CLas population. Bacterial multiplication can be inferred from plants continuing to show bacterial rDNA amplification over the 12-month experiment in leaves flushed after inoculation. This multiplication was diminished in transgenic lines overall and particularly so for late onset cohorts. CLas titer was low enough that many individual samples of leaf and root tissue contained too few copies of the CLas genome to be detectable.

Measurement of CLas titers thro-

In this study, InvA1419 and TolC1314 transgenic lines showed a decreased CLas titer compared with WT controls maintained under the same conditions. Although the transgenic populations averaged higher $\mathrm{C}_{\mathrm{T}}$ values, the effect was not uniform. Individual replicates appeared to segregate into either resistant/late-onset or susceptible/early-onset phenotypes. Late-onset plants maintained markedly reduced $C$ Las titer (higher $\mathrm{C}_{\mathrm{T}}$ ) over the course of the experiment (Table 3) and nearly undetectable levels of $C$ Las in root tissue (Table 4). Early-onset plants had outcomes and characteristics similar to WT control plants. The majority of transgenic individuals can be grouped into the late-onset/resistant type, causing the overall reduction in average CLas titer for transgenics. ugh qPCR amplification of 16S rDNA is the current standard for HLB research. The resulting $C_{T}$ value serves as a fairly close logarithmic proxy for CLas titer; it is quantifiable and can be measured before disease symptoms. Such symptoms may take many months to develop. However, $\mathrm{C}_{\mathrm{T}}$ is not perfectly correlated to disease progression. Symptomatic leaves may have no detectable levels of $C$ Las and asymptomatic leaves may test positive (Louzada et al., 2016). Many cultivars that are considered more tolerant of HLB infection (able to maintain canopy size and growth) carry a high titer of CLas cells (Miles et al., 2017). Full understanding of the impacts of scFv expression will require further studies to determine whether the reduced titer results in 
Table 2. Average Candidatus Liberibacter asiaticus (CLas) cycle threshold $\left(\mathrm{C}_{\mathrm{T}}\right)$ from leaf samples of wild-type (WT) and transgenic 'Carrizo' citrange in the 12 months. following asian citrus psyllid (ACP) infestation. Transgenic lines (TolC1314-A, TolC1314-B, InvA1419-A, InvA1419-B) expressed single chain fragment variable (scFv) antibodies 1314 and 1419, targeting CLas antigens. Groups of 10 clonal replicates of each transgenic line and 20 WT plants were inoculated by no choice feeding from CLas + ACP and maintained at greenhouse conditions. For calculations, undetermined amplification samples were substituted with a $40 \mathrm{C}_{\mathrm{T}}$ value.

\begin{tabular}{|c|c|c|c|c|c|c|c|c|}
\hline \multirow[b]{2}{*}{ Lines } & \multicolumn{2}{|l|}{$3 \mathrm{mo.}$} & \multicolumn{2}{|l|}{$6 \mathrm{mo}}$. & \multicolumn{2}{|l|}{$9 \mathrm{mo.}$} & \multicolumn{2}{|c|}{$12 \mathrm{mo}}$. \\
\hline & $\mathrm{C}_{\mathrm{T}}($ mean $\pm \mathrm{sE})$ & $P$ & $\mathrm{C}_{\mathrm{T}}($ mean $\pm \mathrm{SE})$ & $P$ & $\mathrm{C}_{\mathrm{T}}($ mean $\pm \mathrm{sE})$ & $P$ & $\mathrm{C}_{\mathrm{T}}($ mean $\pm \mathrm{sE})$ & $P$ \\
\hline$\overline{\mathrm{WT}}$ & $27.43 \pm 1.72$ & - & $22.65 \pm 1.79$ & - & $25.64 \pm 1.76$ & - & $27.76 \pm 1.80$ & - \\
\hline TolC1314-A & $33.45 \pm 4.35$ & $0.08^{z}$ & $26.18 \pm 3.55$ & 0.30 & $31.56 \pm 4.43$ & 0.09 & $30.64 \pm 4.49$ & 0.61 \\
\hline TolC1314-B & $32.82 \pm 2.94$ & 0.22 & $29.39 \pm 3.17$ & 0.09 & $32.09 \pm 2.27$ & 0.01 & $33.84 \pm 2.85$ & 0.10 \\
\hline InvA1419-A & $34.92 \pm 2.62$ & 0.05 & $30.34 \pm 2.53$ & 0.01 & $33.69 \pm 2.15$ & 0.02 & $33.51 \pm 2.79$ & 0.09 \\
\hline InvA1419-B & $33.31 \pm 2.60$ & 0.06 & $29.02 \pm 3.09$ & 0.08 & $30.47 \pm 3.21$ & 0.07 & $32.84 \pm 2.87$ & 0.20 \\
\hline
\end{tabular}

${ }^{\mathrm{z}}$ Statistical comparison for all constructs were made against WT by Wilcoxon tests.

Table 3. Average Candidatus Liberibacter asiaticus (CLas) cycle threshold $\left(\mathrm{C}_{\mathrm{T}}\right)$ in leaves from early- and late-onset populations of transgenics 'Carrizo' citrange compared with wild-type (WT) for 12 months after inoculation. Transgenic (TolC1314-A, TolC1314-B, InvA1419-A, InvA1419-B) and WT plants were subdivided into two cohorts based on CLas amplification at 3 months. Early groups $\left(\mathrm{WT}_{\mathrm{E}}, 1314-\mathrm{A}_{\mathrm{E}}, 1314-\mathrm{B}_{\mathrm{E}}, 1419-\mathrm{A}_{\mathrm{E}}, 1419-\mathrm{B}_{\mathrm{E}}\right)$ contain plants with detectable $C$ Las titers at 3 months, and late groups $\left(\mathrm{WT}_{\mathrm{L}}, 1314-\mathrm{A}_{\mathrm{L}}\right.$, $1314-\mathrm{B}_{\mathrm{E}}, 1419-\mathrm{A}_{\mathrm{E}}, 1419-\mathrm{B}_{\mathrm{E}}$ ) having initial detection after 3 months. Undetermined amplification samples were calculated as $\mathrm{C}_{\mathrm{T}} 40$.

\begin{tabular}{|c|c|c|c|c|c|c|c|c|c|}
\hline \multirow[b]{2}{*}{ Lines } & \multirow[b]{2}{*}{ Cohort } & \multicolumn{2}{|l|}{3 mo. } & \multicolumn{2}{|l|}{$6 \mathrm{mo}}$. & \multicolumn{2}{|l|}{9 mo. } & \multicolumn{2}{|l|}{$12 \mathrm{mo}}$. \\
\hline & & $\mathrm{C}_{\mathrm{T}}($ mean $\pm \mathrm{sE})$ & $P$ & $\mathrm{C}_{\mathrm{T}}($ mean $\pm \mathrm{SE})$ & $P$ & $\mathrm{C}_{\mathrm{T}}($ mean $\pm \mathrm{SE})$ & $P$ & $\mathrm{C}_{\mathrm{T}}($ mean $\pm \mathrm{SE})$ & $P$ \\
\hline \multirow[t]{2}{*}{$\overline{\mathrm{WT}}$} & & $27.4 \pm 1.7$ & & $22.7 \pm 1.8$ & & $25.6 \pm 1.8$ & & $27.8 \pm 1.8$ & \\
\hline & $\mathrm{WT}_{\mathrm{L}}$ & 40 & 0.02 & $25.2 \pm 4.4$ & 0.91 & $30.3 \pm 4.2$ & 0.51 & $29.8 \pm 5.9$ & 0.97 \\
\hline \multicolumn{10}{|c|}{ TolC1314-A } \\
\hline & $1314-A_{E}$ & $25.3 \pm 1.7$ & 1.00 & $18.8 \pm 0.8$ & 0.61 & $24.6 \pm 4.7$ & 0.82 & $23.5 \pm 3.3$ & 0.19 \\
\hline Tolcl & $1314-\mathrm{B}_{\mathrm{E}}$ & $22.1 \pm 0.6$ & 0.20 & $18.2 \pm 0.3$ & 0.42 & $25.6 \pm 3.7$ & 0.46 & $30.9 \pm 5.3$ & 0.58 \\
\hline & $1314-\mathrm{B}_{\mathrm{L}}$ & 40 & $<0.01$ & $36.9 \pm 1.4$ & $<0.01$ & $36.4 \pm 0.8$ & $<0.01$ & $35.8 \pm 3.3$ & 0.07 \\
\hline \multicolumn{10}{|c|}{ InvA1419-A } \\
\hline & $1419-\mathrm{A}_{\mathrm{E}}$ & $23.1 \pm 1.6$ & 0.49 & $19.2 \pm 0.6$ & 0.62 & $26.1 \pm 4.4$ & 1.00 & $32.9 \pm 5.6$ & 0.36 \\
\hline & $1419-\mathrm{A}_{\mathrm{L}}$ & 40 & $<0.01$ & $35.1 \pm 1.0$ & $<0.01$ & $36.9 \pm 1.1$ & $<0.01$ & $33.4 \pm 3.5$ & 0.11 \\
\hline
\end{tabular}

${ }^{\mathrm{z}}$ Statistical comparison for all cohorts were made against the mean of pooled WT by Wilcoxon tests.

an agronomically meaningful reduction in disease symptoms and concomitant enhanced crop production under field growing conditions. Farm and dooryard citrus in the field are constantly subjected to reinoculation, which is an important factor in HLB epidemiology (da Graça et al., 2016; Stansly et al., 2014). It will also be important to determine to what extent a transgenic rootstock can confer resistance to a grafted scion. The positive outcomes here were associated with undetectable CLas levels in root tissue. This may be significant because root damage and early colonization of root tissues is associated with CLas pathogenicity, appearing even before foliar symptoms (Graham et al., 2013; Johnson et al., 2014).

Although the transgenic populations overall showed improved HLB resistance in this study, the clear segregation into resistant and susceptible individual plants within the clonal population remains an unresolved question. Replicates from the same line would be expected to have identical genetics, including transgene insert number and location. At 6 months postinfestation, when the variation between clonal replicates was observed, plants from each construct were sampled to check mRNA expression. There existed the possibility that a chimeric parent plant could have produced both transgenic and nontransgenic replicates. This does not appear to be the case as all replicates were confirmed to possess the transgene insertions and to be expressing mRNA. The quantity of transgene mRNA produced did vary slightly between individuals. Expression in TolC1314 plants at 6 months did show a potential positive correlation to $C$ Las $C_{T}$ in linear regression analysis. However, this correlation was not seen with InvA1419 and was not present when TolC1314 plants were retested at 9 and 12 months (Supplemental Fig. 2). These results do not suggest a direct relationship between $\mathrm{scFv}$ mRNA expression and Clas titer. It is possible that posttranscriptional factors are preventing accumulation or activity of the $\mathrm{scFv}$ proteins. Such variations in the protein expression of clonal propagates is unusual but some examples have been previously reported. Potato (Solanum tuberosum) plants originating from one line (GNA2\#74) expressing a defensive protein under a Cauliflower mosaic virus $35 \mathrm{~s}$ promoter were found to have a high level of variability in protein accumulation (including several plants with undetectable levels) when grown under glasshouse conditions (Down et al., 2001). The lower accumulation in that case was also correlated to the loss of the normally conferred resistance to insect feeding. In another study, $\beta$-glucuronidase (GUS) activity driven by the rice actin1 promoter was found to be highly variable in vegetative 
Table 4. Average Candidatus Liberibacter asiaticus (CLas) cycle threshold $\left(\mathrm{C}_{\mathrm{T}}\right)$ from root samples of 'Carrizo' citrange collected 12 months after inoculation. Transgenic (TolC1314-A, TolC1314-B, InvA1419-A, InvA1419-B) and wild-type (WT) populations were grouped into cohorts based on first detection of $C$ Las. The early cohorts $\left(\mathrm{WT}_{\mathrm{E}}, 1314-\mathrm{A}_{\mathrm{E}}, 1314-\mathrm{B}_{\mathrm{E}}, 1419-\mathrm{A}_{\mathrm{E}}\right.$, $1419-\mathrm{B}_{\mathrm{E}}$ ) with detection at 3 months postinoculation and late cohorts $\left(\mathrm{WT}_{\mathrm{L}}, 1314-\mathrm{A}_{\mathrm{L}}, 1314-\mathrm{B}_{\mathrm{E}}, 1419-\mathrm{A}_{\mathrm{E}}, 1419-\mathrm{B}_{\mathrm{E}}\right)$ with first detection any time after 3 months. Samples with undetermined amplification were treated as $\mathrm{C}_{\mathrm{T}} 40$ for calculations.

\begin{tabular}{llcc}
\hline Lines & Cohorts & $\mathrm{C}_{\mathrm{T}}($ mean $\pm \mathrm{sE})$ & $P$ \\
\hline WT & & & \\
& $\mathrm{WT}_{\mathrm{E}}$ & $33.3 \pm 0.9$ & $1.00^{\mathrm{z}}$ \\
TolC1314-A & $\mathrm{WT}_{\mathrm{L}}$ & $34.3 \pm 2.4$ & \\
& & & 0.06 \\
TolC1314-B & $1314-\mathrm{A}_{\mathrm{E}}$ & $29.6 \pm 1.6$ & \\
& $1314-\mathrm{A}_{\mathrm{L}}$ & $37.2 \pm 1.7$ & $<0.01$ \\
& & & \\
InvA1419-A & $1314-\mathrm{B}_{\mathrm{E}}$ & $30.4 \pm 0.7$ & $<0.01$ \\
& $1314-\mathrm{B}_{\mathrm{L}}$ & 40 & \\
& & & \\
InvA1419-B & $1419-\mathrm{A}_{\mathrm{E}}$ & $28.0 \pm 0.6$ & $<0.01$ \\
\hline & $1419-\mathrm{A}_{\mathrm{L}}$ & $39.3 \pm 0.7$ & \\
& & & \\
& $1419-\mathrm{B}_{\mathrm{E}}$ & $31.3 \pm 0.5$ & 40 \\
\hline
\end{tabular}

${ }^{\mathrm{z}}$ Statistical comparisons for all late onset cohorts were made against WTE by Wilcoxon tests.

propagated Festuca arundinacea plants (Bettany et al., 1998). Additional work will need to be done to determine if the variability in HLB resistance we observed was the result of differences in protein synthesis. Unfortunately, HLB is the result of an extremely complex interaction among the citrus host, insect vector, and bacterial pathogen. The disease outcome may well be determined at some currently unknown key stages or through some unsuspected mode of action. A greater understanding of the disease progression will likely be needed to determine what factors cause the observed divergence in resistance levels. The results of this study suggest that transgenically expressed scFvs targeting TolC and InvA may confer protection against CLas. However, the durability and strength of any resistance conferred by expression in rootstocks to a grafted tree maintained in the field is still to be determined.

\section{Literature Cited}

Barbas, C.F., III, D.R. Burton, J.K. Scott, and G.J. Silverman. 2001. Phage display: A laboratory manual. Cold Springs Harbor Lab. Press, Cold Springs Harbor, NY.

Bastianel, C., M. Garnier-Semancik, J. Renaudin, J.M. Bové, and S. Eveillard. 2005. Diversity of Candidatus Liberibacter asiaticus, based on the omp gene sequence. Appl. Environ. Microbiol. 71:6473-6478, doi: 10.1128/AEM.71.11.6473-6478.2005.

Bettany, A.J.E., S.J. Dalton, E. Timms, and P. Morris. 1998. Stability of transgene expression during vegetative propagation of protoplastderived tall fescue (Festuca arundinacea Schreb.) plants. J. Expt. Bot. 49:1797-1804, doi: 10.1093/jxb/49.328.1797.

Blair, J.M. and L.J. Piddock. 2009. Structure, function and inhibition of RND efflux pumps in Gram-negative bacteria: An update. Curr. Opin. Microbiol. 12:512-519, doi: 10.1016/j.mib.2009.07.003.
Bové, J.M. 2006. Huanglongbing: A destructive, newly-emerging, century-old disease of citrus. J. Plant Pathol. 88:7-37, doi: 10.4454/jpp. v88i1.828.

Capoor, S.P., D.G. Rao, and S.M. Viswanath. 1967. Diaphorina citri Kuway., a vector of the greening disease of citrus in India. Indian J. Agr. Sci. 37:572-576.

Chen, Y.D. and T.A. Chen. 1998. Expression of engineered antibodies in plants: A possible tool for spiroplasma and phytoplasma disease control. Phytopathology 88:1367-1371, doi: 10.1094/PHYTO.1998. 88.12.1367.

Cimò, G., R.L. Bianco, P. Gonzalez, W. Bandaranayake, E. Etxeberria, and J.P. Syvertsen. 2013. Carbohydrate and nutritional responses to stem girdling and drought stress with respect to understanding symptoms of huanglongbing in citrus. HortScience 48:920, doi: 10.21273/hortsci.48.7.920.

Cserzö, M., E. Wallin, I. Simon, G. von Heijne, and A. Elofsson. 1997. Prediction of transmembrane alpha-helices in prokaryotic membrane proteins: The dense alignment surface method. Protein Eng. 10:673-676, doi: 10.1093/protein/10.6.673.

da Graça, J.V., G.W. Douhan, S.E. Halbert, M.L. Keremane, R.F. Lee, G. Vidalakis, and H. Zhao. 2016. Huanglongbing: An overview of a complex pathosystem ravaging the world's citrus. J. Integr. Plant Biol. 58:373-387, doi: 10.1111/jipb.12437.

da Graça, J.V. and L. Korsten. 2004. Citrus huanglongbing: Review, present status and future strategies, p. 229-245. In: S.A.M.H. Naqvi (ed.). Diseases of fruits and vegetables volume I: Diagnosis and management. Kluwer Academic Publ., Dordrecht, The Netherlands, doi: 10.1007/1-4020-2606-4_4.

Davis, M.J., S.N. Mondal, H. Chen, M.E. Rogers, and R.H. Brlansky. 2008. Co-cultivation of Candidatus Liberibacter asiaticus with actinobacteria from citrus with huanglongbing. Plant Dis. 92:1547-1550, doi: 10.1094/PDIS-92-11-1547.

Down, R.E., L. Ford, S.J. Bedford, L.N. Gatehouse, C. Newell, J.A. Gatehouse, and A.M.R. Gatehouse. 2001. Influence of plant development and environment on transgene expression in potato and consequences for insect resistance. Transgenic Res. 10:223-236, doi: 10.1023/A:1016612912999.

Duan, Y., L. Zhou, D.G. Hall, W. Li, H. Doddapaneni, H. Lin, L. Liu, C.M. Vahling, D.W. Gabriel, K.P. Williams, A. Dickerman, Y. Sun, and T. Gottwald. 2009. Complete genome sequence of citrus huanglongbing bacterium, Candidatus Liberibacter asiaticus obtained through metagenomics. Mol. Plant Microbe Interact. 22:1011-1020, doi: 10.1094/mpmi-22-8-1011.

Gaywee, J., J.B. Sacci, Jr., S. Radulovic, M.S. Beier, and A.F. Azad. 2003. Subcellular localization of rickettsial invasion protein. InvA. Amer. J. Trop. Med. Hygiene 68:92-96.

Gaywee, J., W. Xu, S. Radulovic, M.J. Bessman, and A.F. Azad. 2002. The Rickettsia prowazekii invasion gene homolog (invA) encodes a Nudix hydrolase active on adenosine $\left(5^{\prime}\right)$-pentaphospho- $\left(5^{\prime}\right)$ adenosine. Mol. Cell. Proteomics 1:179-185, doi: 10.1074/mcp. m100030-mcp200.

Gottwald, T.R. 2010. Current epidemiological understanding of citrus huanglongbing. Annu. Rev. Phytopathol. 48:119-139, doi: 10.1146/ annurev-phyto-073009-114418.

Gottwald, T.R., J.V.d. Graça, and R.B. Bassanezi. 2007. Citrus huanglongbing: The pathogen and its impact. Plant Health Prog. 8:31, doi: 10.1094/PHP-2007-0906-01-RV.

Graham, J.H., E.F. Johnson, T.R. Gottwald, and M.S. Irey. 2013. Presymptomatic fibrous root decline in citrus trees caused by huanglongbing and potential interaction with Phytophthora spp. Plant Dis. 97:1195-1199, doi: 10.1094/PDIS-01-13-0024-RE.

Griep, R.A., C. van Twisk, J.R. van Beckhoven, J.M. van der Wolf, and A. Schots. 1998. Development of specific recombinant monoclonal antibodies against the lipopolysaccharide of Ralstonia solanacearum Race 3. Phytopathology 88:795-803, doi: 10.1094/phyto.1998.88. 8.795 . 
Hao, G., M. Pitino, Y. Duan, and E. Stover. 2016. Reduced susceptibility to Xanthomonas citri in transgenic citrus expressing the FLS2 receptor from Nicotiana benthamiana. Mol. Plant Microbe Interact. 29:132-142, doi: 10.1094/MPMI-09-15-0211-R.

Hartung, J., C. Paul, D. Achor, and R. Brlansky. 2010. Colonization of dodder, Cuscuta indecora, by Candidatus Liberibacter asiaticus and Ca. L. americanus. Phytopathology 100:756-762, doi: 10.1094/ PHYTO-100-8-0756.

Hiatt, A., R. Caffferkey, and K. Bowdish. 1989. Production of antibodies in transgenic plants. Nature 342:76-78, doi: 10.1038/342076a0.

Hofgen, R. and L. Willmitzer. 1988. Storage of competent cells for Agrobacterium transformation. Nucleic Acids Res. 16:9877, doi: 10.1093/nar/16.20.9877.

Hudson, P.J. and A.A. Kortt. 1999. High avidity scFv multimers; diabodies and triabodies. J. Immunol. Methods 231:177-189, doi: 10.1016/S0022-1759(99)00157-X.

Jagoueix, S., J.M. Bové, and M. Garnier. 1994. The phloem-limited bacterium of greening disease of citrus is a member of the $\alpha$ subdivision of the Proteobacteria. Intl. J. Syst. Bacteriol. 44:379-386, doi: 10.1099/00207713-44-3-379.

Johnson, E.G., J. Wu, D.B. Bright, and J.H. Graham. 2014. Association of Candidatus Liberibacter asiaticus root infection, but not phloem plugging with root loss on huanglongbing-affected trees prior to appearance of foliar symptoms. Plant Pathol. 63:290-298, doi: 10.1111/ppa.12109.

Li, W., J.S. Hartung, and L. Levy. 2006. Quantitative real-time PCR for detection and identification of Candidatus Liberibacter species associated with citrus huanglongbing. J. Microbiol. Methods 66:104-115, doi: 10.1016/j.mimet.2005.10.018.

Liu, H., S. Atta, and J.S. Hartung. 2017. Characterization and purification of proteins suitable for the production of antibodies against $\mathrm{Ca}$. Liberibacter asiaticus. Protein Expr. Purif. 139:36-42, doi: 10.1016/j. pep.2017.07.010.

Louzada, E.S., O.E. Vazquez, W.E. Braswell, G. Yanev, M. Devanaboina, and M. Kunta. 2016. Distribution of Candidatus Liberibacter asiaticus above and below ground in Texas citrus. Phytopathology 106:702-709, doi: 10.1094/PHYTO-01-16-0004-R.

Madeira, F., Y.M. Park, J. Lee, N. Buso, T. Gur, N. Madhusoodanan, P. Basutkar, A.R.N. Tivey, S.C. Potter, R.D. Finn, and R. Lopez. 2019. The EMBL-EBI search and sequence analysis tools APIs in 2019. Nucleic Acids Res. 47:W636-W641, doi: 10.1093/nar/gkz268.

McClean, A.P.D. and R.E. Schwarz. 1970. Greening or blotchy-mottle disease of citrus. Phytophylactica 2:177-194.

McKenzie, C.L. and R.G. Shatters. 2009. First report of Candidatus Liberibacter psyllaurous associated with psyllid yellows of tomato in Colorado. Plant Dis. 93:1074, doi: 10.1094/PDIS-93-10-1074A.

Merfa, M.V., E. Perez-Lopez, E. Naranjo, M. Jain, D.W. Gabriel, and L. De La Fuente. 2019. Progress and obstacles in culturing Candidatus Liberibacter asiaticus, the bacterium associated with huanglongbing. Phytopathology 109:1092-1101, doi: 10.1094/phyto-02-19-0051-rvw.

Miles, G.P., E. Stover, C. Ramadugu, M.L. Keremane, and R.F. Lee. 2017. Apparent tolerance to huanglongbing in citrus and citrusrelated germplasm. HortScience 52:31-39, doi: 10.21273/HORTSCI 11374-16.

Morgan, J.K., L. Zhou, W. Li, R.G. Shatters, M. Keremane, and Y. Duan. 2012. Improved real-time PCR detection of Candidatus
Liberibacter asiaticus from citrus and psyllid hosts by targeting the intragenic tandem-repeats of its prophage genes. Mol. Cell. Probes 26:90-98, doi: 10.1016/j.mcp.2011.12.001.

Murray, R.G. and E. Stackebrandt. 1995. Taxonomic note: Implementation of the provisional status Candidatus for incompletely described procaryotes. Intl. J. Syst. Evol. Microbiol. 45:186-187, doi: 10.1099/ 00207713-45-1-186.

Pavoni, E., G. Monteriù, M. Cianfriglia, and O. Minenkova. 2007. New display vector reduces biological bias for expression of antibodies in E. coli. Gene 391:120-129, doi: 10.1016/j.gene.2006.12.009.

Reddy, J.D., S.L. Reddy, D.L. Hopkins, and D.W. Gabriel. 2007. TolC is required for pathogenicity of Xylella fastidiosa in Vitis vinifera grapevines. Mol. Plant Microbe Interact. 20:403-410, doi: 10.1094/mpmi-20-4-0403.

Sauer, A.V., C.A. Zanutto, P.T.R. Nocchi, M.A. Machado, C.H. Bock, and W.M.C. Nunes. 2015. Seasonal variation in populations of Candidatus Liberibacter asiaticus in citrus trees in Paraná State, Brazil. Plant Dis. 99:1125-1132, doi: 10.1094/pdis-09-14-0926-re.

Schots, A., J. De Boer, A. Schouten, J. Roosien, J.F. Zil Verentant, H. Pomp, L. Bouwman-Smits, H. Overmars, F.J. Gommers, B. Visser, W.J. Stiekema, and J. Bakker. 1992. "Plantibodies": A flexible approach to design resistance against pathogens. Neth. J. Plant Pathol. 98:183-191, doi: 10.1007/BF01974485.

Stansly, P.A., H.A. Arevalo, J.A. Qureshi, M.M. Jones, K. Hendricks, P.D. Roberts, and F.M. Roka. 2014. Vector control and foliar nutrition to maintain economic sustainability of bearing citrus in Florida groves affected by huanglongbing. Pest Manag. Sci. 70:415-426, doi: $10.1002 /$ ps.3577.

Stover, E., S. Inch, M.L. Richardson, and D.G. Hall. 2016. Conventional citrus of some scion/rootstock combinations show field tolerance under high huanglongbing disease pressure. HortScience 51:127-132, doi: 10.21273/HORTSCI.51.2.127.

Tavladoraki, P., E. Benvenuto, S. Trinca, D. De Martinis, A. Cattaneo, and P. Galeffi. 1993. Transgenic plants expressing a functional single-chain $\mathrm{Fv}$ antibody are specifically protected from virus attack. Nature 366:469-472, doi: 10.1038/366469a0.

Vartanian, A., I. Prudovsky, H. Suzuki, I. Dal Pra, and L. Kisselev. 1997. Opposite effects of cell differentiation and apoptosis on Ap3A/ Ap4A ratio in human cell cultures. FEBS Lett. 415:160-162, doi: 10.1016/S0014-5793(97)01086-7.

Wang, N. and P. Trivedi. 2013. Citrus huanglongbing: A newly relevant disease presents unprecedented challenges. Phytopathology 103:652-665, doi: 10.1094/phyto-12-12-0331-rvw.

Yuan, Q., R. Jordan, R.H. Brlansky, O. Istomina, and J. Hartung. 2015. Development of single chain variable fragment (scFv) antibodies against Xylella fastidiosa subsp. pauca by phage display. J. Microbiol. Methods 117:148-154, doi: 10.1016/j.mimet.2015.07.020. Yuan, Q., R. Jordan, R.H. Brlansky, O. Minenkova, and J. Hartung. 2016. Development of single chain variable fragment (scFv) antibodies against surface proteins of $\mathrm{Ca}$. Liberibacter asiaticus. J. Microbiol. Methods 122:1-7, doi: 10.1016/j.mimet.2015.12.015.

Zhang, M., C.A. Powell, Y. Guo, L. Benyon, and Y. Duan. 2013. Characterization of the microbial community structure in Candidatus Liberibacter asiaticus-infected citrus plants treated with antibiotics in the field. BMC Microbiol. 13:112, doi: 10.1186/1471-2180-13-112. 


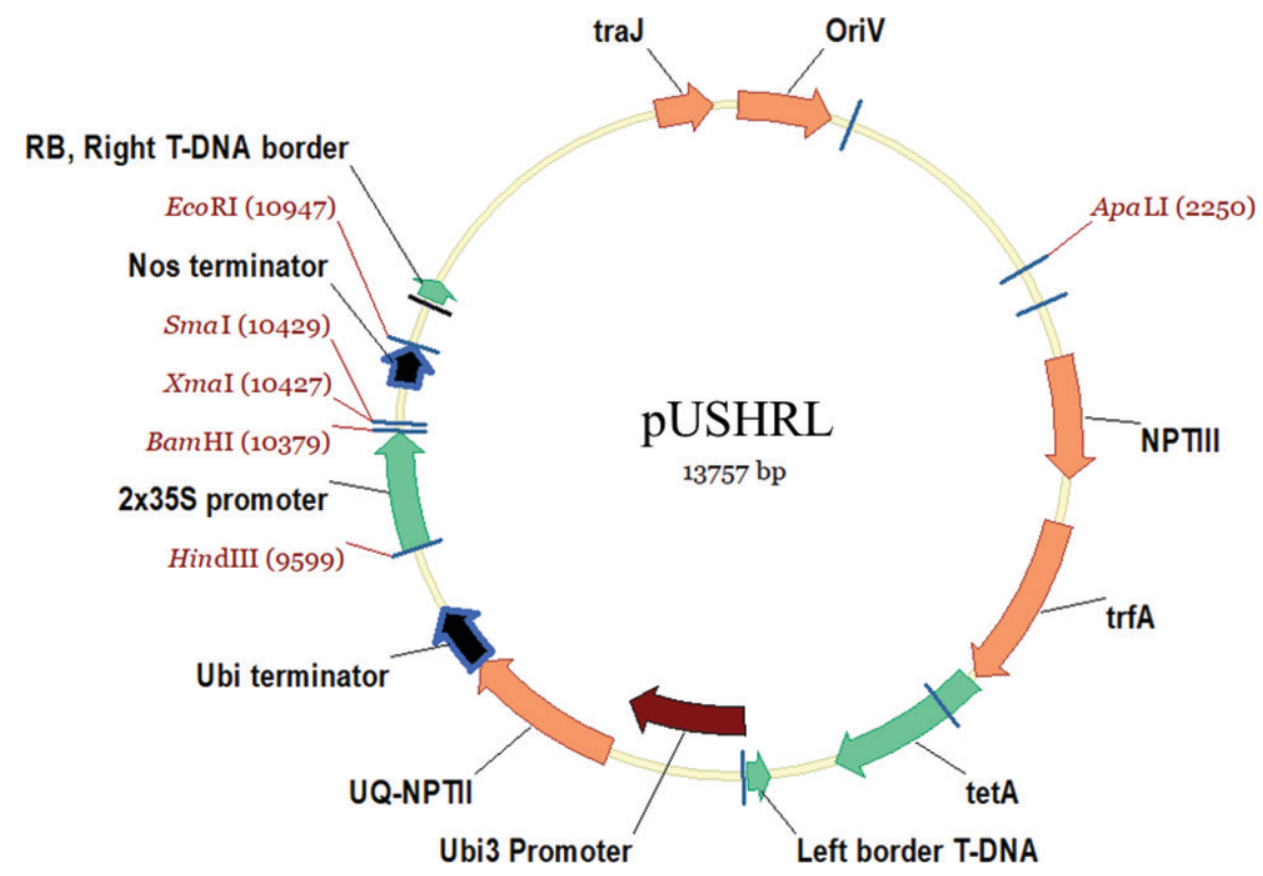

Supplemental Fig. 1. Map of the binary transformation plasmid pUSHRL. Located in the transfer DNA (T-DNA) region between the left and right border sequences is a selective marker for kanamycin resistance expressing an ubiquitin monomer/neomycin phosphotransferase II enzyme (UQ-NPTII) fusion under control of a Solanum tuberosum ubiquitin/ribosomal fusion protein (ubi3) gene promoter and terminator. A second T-DNA gene includes a tandem Cauliflower mosaic virus $35 \mathrm{~S}(2 \times 35 \mathrm{~S})$ promoter and nopaline synthase (NOS) terminator flanking cloning sites suitable for inserting a sequence of interest to express. The remaining plasmid backbone contains an origin of vegetative replication (OriV) and genes for neomycin phosphotransferase III (NPTIII), tetracycline resistance protein TetA, plasmid replication initiator protein TrfA and protein TraJ.

A

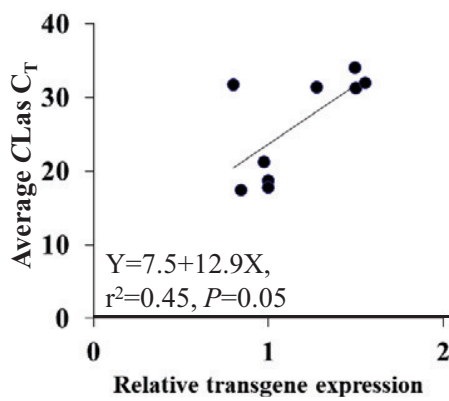

B

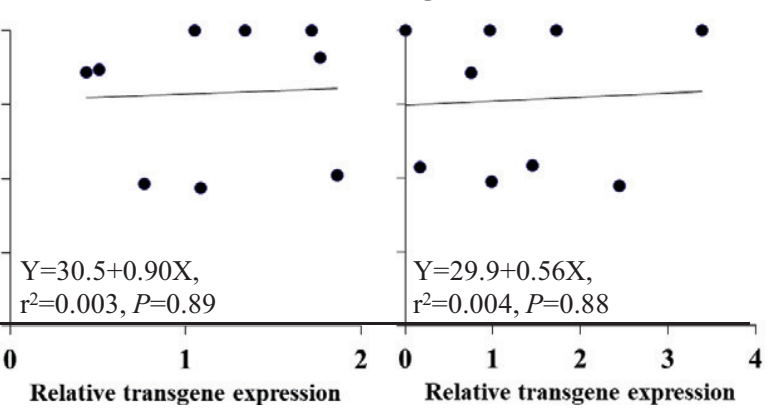

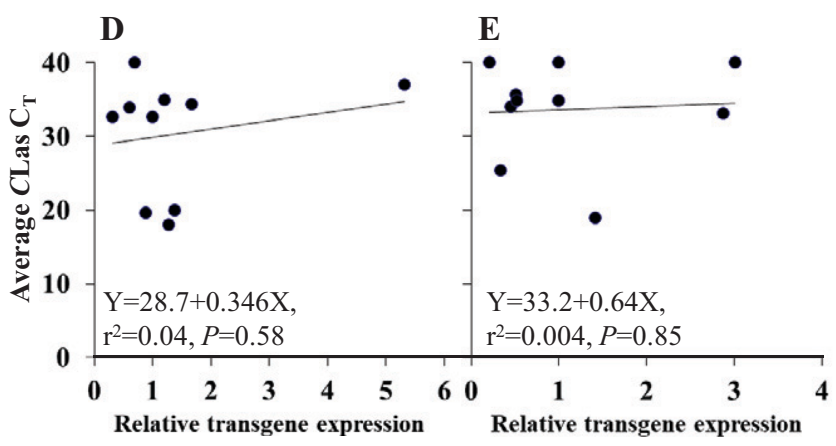

Supplemental Fig. 2. Comparison of Candidatus Liberibacter asiaticus (CLas) levels in 'Carrizo' citrange leaves to single chain fragment variable (scFv) expression. Clonal replicates of transgenic lines scFv-TolC1314A and scFv-InvA1419A were analyzed for relative expression of scFv transgene mRNA by reverse transcriptase and quantitative real-time polymerase chain reactions (qPCR) using a theoretical $2^{\mathrm{N}}$ quantification. Plants of scFv-TolC1314A were assessed at 6 months (A), 9 months (B), and 12 months (C) and scFv-InvA1419A at 6 months (D) and 9 months (E) after CLas inoculation. Transgene expression levels were compared to the average CLas $16 \mathrm{~S}$ ribosomal DNA cycle threshold $\left(\mathrm{C}_{\mathrm{T}}\right)$ as determined by qPCR of samples from the same plants at the corresponding time points. A simple linear regression was used to model potential direct relationships between the measurements. 